\title{
Climate Change Mitigation and the Role of Technological Change: Impact on selected headline targets of Europe's 2020 climate and energy package
}

\author{
Germà Bel \& Stephan Joseph (Universitat de Barcelona) \\ (Paper forthcoming in Renewable \& Sustainable Energy Reviews, 2018)
}

\begin{abstract}
The European Union launched a set of policies as part of its 2020 climate and energy package aimed at meeting its 20/20/20 headline targets for smart, sustainable and inclusive growth. This paper evaluates how successful new-to-the-market climate change mitigation technologies (CCMT) are in helping EU member states (MS) reach these goals and, furthermore, whether there are differences between sectors subject to EU-wide polices. To do so, we relate CCMT patent counts to two specific headline targets: (1) achieving $20 \%$ of gross final energy consumption from renewables, and (2) achieving a 20\% increase in energy efficiency. Our results provide the first expost evaluation of the effectiveness of these technologies for combating climate change. Moreover, our sectoral impact assessment points to significant differences in the way in which these technologies contribute to policy goals across the sectors.
\end{abstract}

Key words: Environmental Policy; Climate Change; Technological Change; Patent Count Data

\section{Introduction}

The first, legally binding global climate deal, adopted by 195 countries in Paris (COP 21) in December 2015, places its participants under considerable pressure. Indeed, as highlighted by the 2014 report on climate change mitigation ([1] Edenhofer et al. 2014), published by the Intergovernmental Panel on Climate Change (IPCC), the headline target of the Paris Agreement limiting global warming to a maximum of two degrees in the long run - will be difficult to achieve unless there are major improvements in energy efficiency. In this regard, the report stresses the key role to be played by policies that can cut demand for energy by fostering investment in energy efficiency projects. In short, the role of technological change as it impacts energy production and end-use is critical for maintaining global warming below two degrees.

Prior to the Paris Agreement, the European Union launched a set of policies as part of its 2020 climate and energy package aimed at meeting its 20/20/20 headline targets for smart, sustainable and inclusive growth. As such, technology change explicitly underpins the EU's policy framework; yet, and to the best our knowledge, there has been no ex-post assessment of the role technology change is playing in achieving these goals. Recent studies in the literature concern themselves, 
primarily, with evaluating the ways in which public environmental policies stimulate "green" technology change, but they do not examine how effective these technologies are in achieving established policy goals and whether their impact varies across sectors.

In this study, therefore, we seek 1) to measure how successful new-to-the-market climate change mitigation technologies (CCMTs) are in helping EU member states (MS) reach these goals and 2) to determine whether their effectiveness varies across sectors subject to these EU-wide polices. To do so, we relate CCMT patent counts to two specific headline targets, namely, achieving at least $20 \%$ of gross final energy consumption from renewables, and achieving a $20 \%$ increase in energy efficiency. Available data allow us to determine the impact of different CCMT classes on overall target achievement, and on sector-specific achievement rates. Our results provide the first ex-post evaluation of the effectiveness of these technologies for combating climate change. Moreover, our impact assessment conducted by sector points to significant differences in the way in which these technologies contribute to policy goals across sectors. In short, our study both broadens understanding of the impact CCMTs can have and serves to make policy recommendations aimed at reaching the ambitious climate goals set by the EU and placing it firmly on the pathway to a lowcarbon future.

The rest of the study is organized as follows. In section two, we present a brief overview of the 2020 climate and energy package and its policies and, so as to provide a clear picture of where the EU currently stands, we report descriptive statistics for its headline targets and CCMT measures. A brief literature review follows, in which we examine the most relevant findings. Next, we introduce the data for the empirical exercise along with their descriptive statistics. In section five, we explain our empirical strategy, and in the next section we present the regression results and discuss the role played by CCMTs. Finally, we conclude the study with a number of policy recommendations and discuss the study's limitations and potential lines of future research.

\section{The EU “2020 climate and energy package” and its policies}

In 2010, the European Commission (EC) established five headline targets - the Europe 2020 Strategy - outlining where the EU should stand on key parameters by 2020 ([2] European Commission 2010). To meet these energy and climate change goals, the EC put together the "2020 climate and energy package", comprising a set of binding regulations to ensure the following targets are met: (1) 20\% reduction in greenhouse gas (GHG) emissions; (2) 20\% of gross final energy consumption from renewables; and (3) 20\% improvement in energy efficiency ([3] European Commission 2016). 


\section{1- $20 \%$ reduction in GHG emissions.}

The main tool devised here is the EU Emissions Trading System (EU ETS), covering around 45\% of Europe's GHG emissions and applicable to energy-intensive industries and, since 2012, to commercial airlines. The tool is complemented by a policy that seeks to reduce emissions - the "Effort Sharing Decision" - and which applies to sectors not covered by the EU ETS (including, transport, housing, waste, and agriculture). However, owing to their differing growth prospects, the policy is not applied homogeneously across MS, the richest having to reduce their emissions by $20 \%$ and the least wealthy being permitted to increase theirs by $20 \%$. Thus, in contrast with the EU ETS, the "Effort Sharing Decision" is dependent on national emission reduction plans.

The EU has made considerable progress towards this first goal, reaching the target being a simple matter of time (Figure 1). By 2012, the EU had achieved an 18\% cut in its 1990 GHG emission levels ([4] Eurostat, 2014a). Yet, this progress cannot be attributed solely to the efforts of the EU; it also reflects the impact of external factors, not least the effects of the 2008/09 economic crisis. As [5] Bel \& Joseph (2015) stress, the main driver of emission abatement for sectors under the EU ETS was the economic recession, and only a relatively small proportion can be attributed to the policy.

Figure 1: EU-28 GHG emissions, 1990-2013

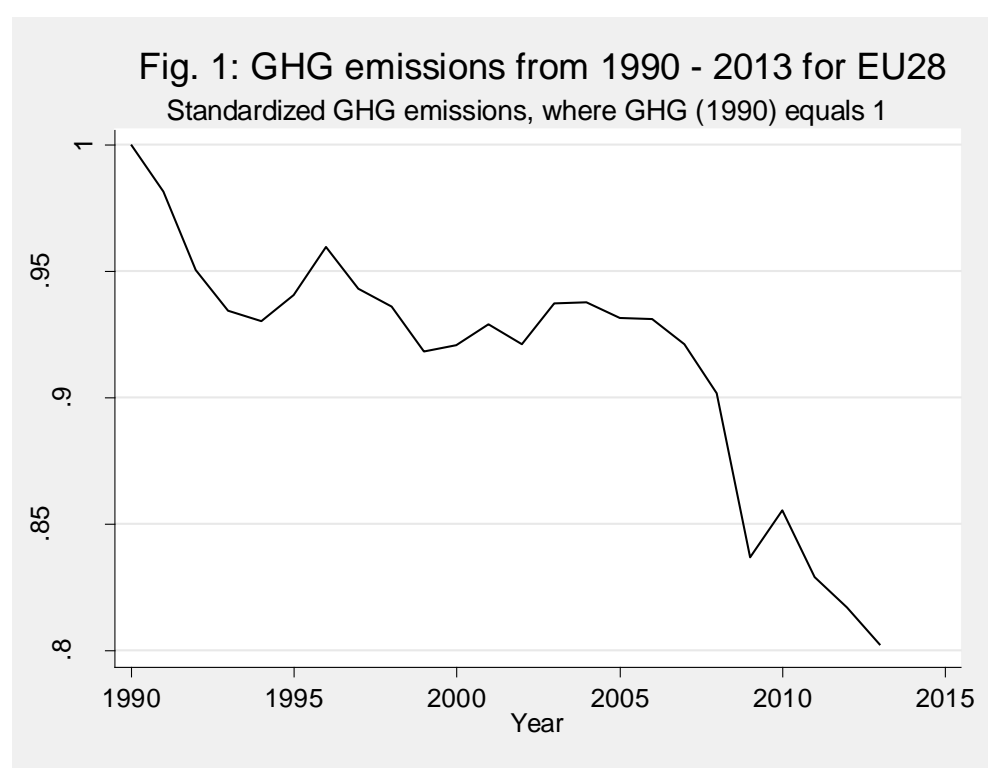


Given that this first goal is within sight, we do not examine the effects of CCMTs and GHG abatement any further. Moreover, this target does not concern our empirical analysis, given that targets 2 and 3 very much condition this first goal: an increase in the share of renewable energy sources in gross inland energy consumption (GIEC) and a reduction in final energy consumption as a result of efficiency enhancements both reduce GHG emissions. On this point, note that the energy savings/efficiency increases outlined in the Energy Efficiency Directive 2012/27/EC do not favor a reduction in the implicit energy price, and so "rebound" effects (as predicted, for example, by [6] Herring 2006) are not expected.

\section{2- $20 \%$ renewable energy share.}

Part of the "Renewable Energy Directive", national renewable targets also vary across MS, depending on their initial position and potential ([7] European Commission 2009). For example, Sweden has been set a target of 49\%, while Malta's is fixed at just 10\% ([8] National Renewable Energy Action Plan Sweden 2010; [9] National Renewable Energy Action Plan Malta 2010). The directive fosters cooperation among MS by promoting three mechanisms: statistical transfers of renewable energy, joint renewable energy projects, and joint renewable energy support schemes. Additionally, it promotes the use of sustainable biofuels in the transport sector to meet a $10 \%$ renewable energy target ([10] European Commission 2015).

Progress has also been made in the sources of renewable energy. GIEC by fuel increased from 8.9 to $13.3 \%$ between 2005 and 2012 (Figures 2 and 3 - "other" includes solid fuels, nuclear heat, and waste), representing a growth of $49 \%$ over the whole period. Yet, all GIEC shares by fuel type dropped, the largest being recorded by petroleum products $(\sim 3 \%)$. These substitution effects are worth stressing given that the burning of fossil fuels (primarily in association with the production of electricity and transport) is one of the main drivers of climate change ([11] EPA 2016; [12] NASA 2016).

This positive overall trend conceals huge differences between countries: Sweden, Bulgaria, and Estonia having already met their 2020 targets, but many, including Malta, Netherlands, the UK, and Luxembourg, are still some distance from meeting their respective goals ([13] Eurostat 2014b). 
Figures $2 \&$ 3: Shares of gross inland energy consumption by fuel type (GIEC), 2005 \& 2012

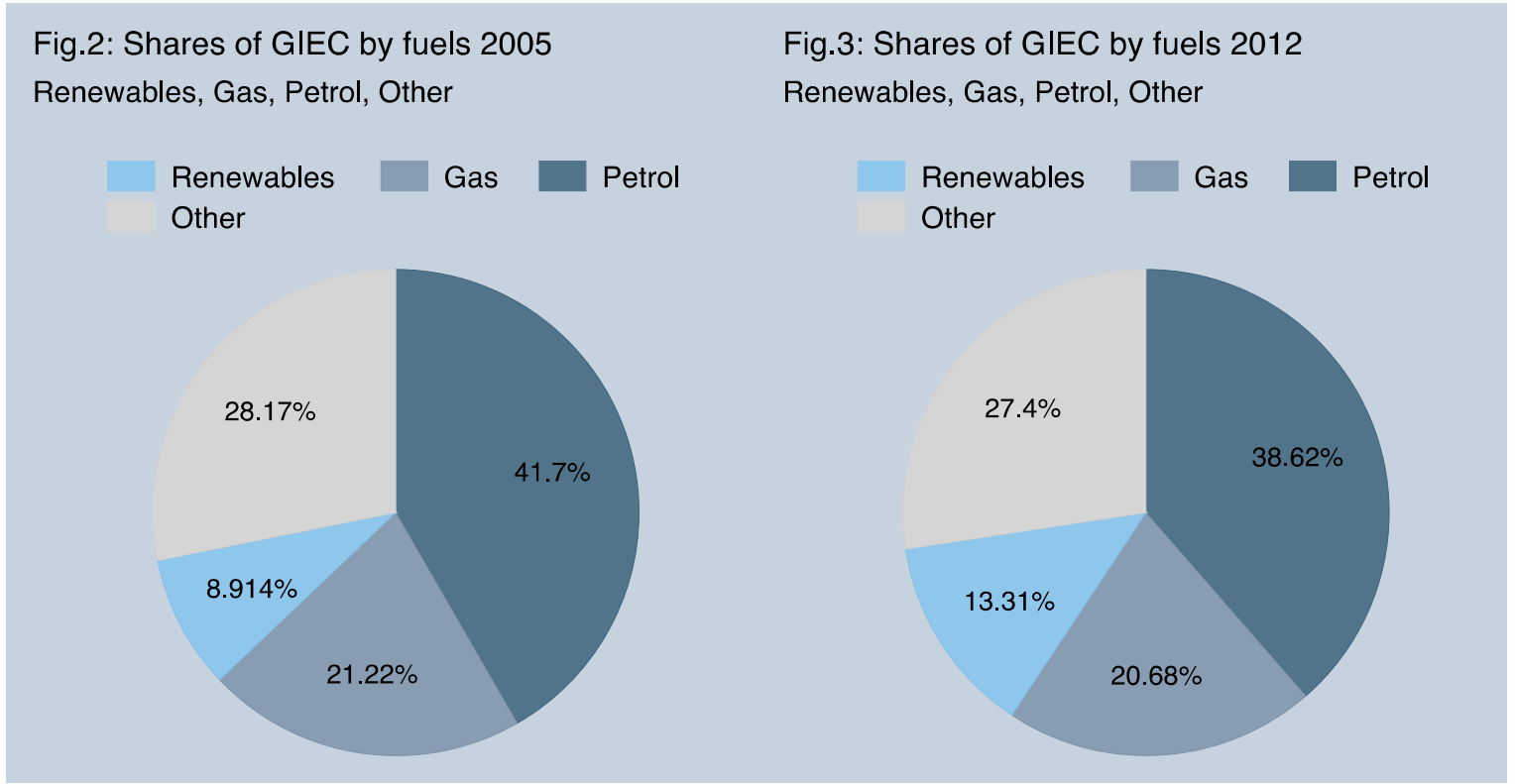

Source: Eurostat \& own calculations

\section{3- $20 \%$ improvement in energy efficiency.}

To help achieve this goal, the EC issued its Energy Efficiency Directive ([14] European Commission 2012), centered on three pillars. The first comprises the National Energy Efficiency Action Plans (NEEAPs) - which include estimated energy consumption levels, planned energy efficiency measures, and the individual goals for each MS - and the annual reports - which serve to verify whether targets have been reached. The NEEAPs have to be revised and resubmitted every three years.

The second pillar comprises the national building renovation strategies, whereby each MS indicates how they intend stimulating investments via the targeting of renovation in the commercial and residential building sectors. The MS are obliged to renovate at least 3\% of their government building stock (or alternatively they may opt to implement behavioral changes or undertake major renovation work that achieves the same degree of energy savings).

The third pillar comprises the energy efficiency obligation schemes, which target energy distributors or retail energy sales companies. Here, the aim is to achieve a $1.5 \%$ energy saving in annual sales to end consumers by implementing efficiency measures. However, MS can opt for alternative policy measures, including energy/carbon taxes, training and education, and financial incentives for the deployment of energy efficiency technologies. 
To assess the achievement of this target, two points need to be borne in mind. First, while various indicators of energy efficiency can be used - including, primary energy consumption (PEC), final energy consumption (FEC), final energy savings, or energy intensity, the EC ruled that national targets be expressed as either PEC or FEC ([15] European Commission 2013). Second, the EC established 2007 as the baseline projection for energy consumption and estimated that 1,853 million tons of oil equivalent (Mtoe) of primary energy will be consumed in 2020 (European Commission 2012). Thus, a $20 \%$ reduction would correspond to a PEC of 1,482 Mtoe or a FEC of 1,086 Mtoe, ([16] The Coalition for Energy Savings 2013).

In our data sample, one sector is responsible for nearly a third of the EU's FEC: transport (31.8\%). This sector is also responsible for 23.2\% of total GHG emissions in the EU28 ([17] Eurostat 2016) and for $27 \%$ of these emissions in the US ([18] Javid et al. 2014). Figure 4 reveals a number of interesting trends in sector-specific FEC. First, the downward trend in the transport sector (following a minor increase between 2005 and 2007) contrasts with the fluctuating consumption in the other sectors, suggesting that consumption in the transport sector is not as volatile to changes in economic performance as it is in the other sectors. So, while FEC in the 'other' sectors (namely, industry, agriculture/forestry, services, residential, and other-non-specified, where industry accounts for the largest share) increased sharply in the period of recovery following the 2008/2009 economic crisis, FEC in the transport sector fell steadily.

Figure 4: Final Energy Consumption (FEC) by Sector

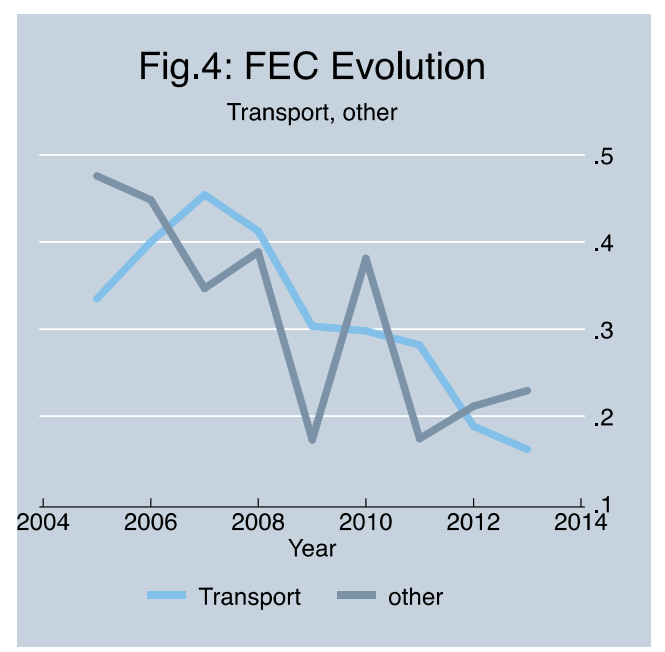

Note: Fig. 4 uses standardized FEC consumption for the sector "other" and the transport sector for comparability reasons. Source: Eurostat \& Own Calculations.

Finally, between 2005 and 2012, energy efficiency increased, while total FEC fell by 7.1\%, although this reduction was not spread evenly across the sectors. FEC in the transport sector fell by only $4.75 \%$, suggesting that the other sectors were responsible for most of this reduction. 


\section{Related literature}

Many recent studies have sought to analyze the relationship between environmental policy impact and technological change. However, studies focusing on the specific impact of new-to-the-market technologies on these policy goals are scarce.

Many authors draw on the "induced innovation" hypothesis, as formulated by [19] Hicks (1932) and later reformulated in terms of environmental policy by [20] Porter \& van der Linde (1995) and renamed the Porter Hypothesis, which states that well-designed environmental policies can foster environment-friendly technological change. [21] Popp (2003), for example, exploits a policy regime change, from a classical command-and-control regime to a market-based approach, to study effects on patenting activity and the effectiveness of new patents, following the introduction of the Clean Air Act in 1990. While patenting activity - measured in patent counts - fell with the introduction of the Act, the focus taken by R\&D activity also shifted. Before the transition, companies concentrated their R\&D efforts on reducing the regulatory compliance costs; after 1990, their R\&D became more concerned with improving the efficiency of technology that could reduce emissions. Although the absolute number of patents fell in 1990, the new market approach increased the efficiency of new patents designed to guarantee a more environment-friendly production.

Using patent data to determine the role of environmental policies in the development of technological innovations in renewable energy sources (RES), [22] Johnstone et al. (2009) show that different policy instruments can favor the innovation of different RES. Overall, the authors report that public policy plays a key role in fostering new-to-the-market technologies: in the case of the more costly RES (e.g. solar energy), targeted policy instruments, such as feed-in-tariffs, have a significant effect; whereas, broad-based policies, such as emission trading, foster technological change that is competitive with conventional energy sources.

[23] Haščič et al. (2010) provide further evidence of the importance of environmental policies in promoting "green" technological change, by identifying a link between climate change policies and the generation and diffusion of CCMTs. However, the authors show that innovation depends not only on public policy, but also on a country's innovative capacity. Thus, there is a classic mismatch between the needs of developing countries with respect to specific CCMTs and their actual development, given a lack of innovative capacity. In contrast, developed countries lack incentives to develop these technologies.

Focusing on the key European climate change mitigation policy, the EU ETS, [24] Calel and Dechezleprêtre (2016) match EU ETS firms with firms not affected by the policy and apply a difference-in-differences estimation as they seek to separate the impact of the policy on the 
development of low-carbon technologies from other external factors. By measuring technological change in terms of the number of patent applications registered at the European Patent Office (EPO), the authors are able to untangle the surge in CCMT patenting that coincided with the launch of the EU ETS in 2005. According to their estimates, the policy was responsible for almost a 1\% increase in CCMTs, when compared to the counterfactual scenario. Furthermore, their firmlevel estimates highlight that the EU ETS has a limited impact on overall low-carbon patenting, but a strong and targeted effect on a small set of firms under the regime.

The study that is most similar to the one we conduct here is [25] Soltmann et al. (2014). Using industry-level panel data, the authors explain the link between green innovation and performance, measured as value added. They report a U-shaped relationship, but as the turning point is high, the associated effect for most industries is negative up to that point. However, they do not address our specific research question regarding the extent to which green technologies can contribute to meeting climate policy targets.

Other studies have explained the link between environmental regulations and technological change ([26] Jaffe \& Palmer (1997), [27] Jaffe et al. (2002), [28] Popp (2006), [29] Anderson et al. (2011), [30] Fontini and Pavan (2014)); but, they each adopt a different focus. However, to the best of our knowledge, no study to date has analyzed the effectiveness of these technologies for the goals established by environmental policy. Therefore, our aim is to provide an initial measure of how CCMTs, in general, contribute to achieving climate and energy targets. In addition, and more specifically, we wish to determine how different branches of these technologies impact sectoral policy measures. To do so, we focus our attention on the European 20/20/20 goals and their corresponding measures and the impact of selected CCMTs, making our study the first, we believe, to undertake an impact assessment of different CCMTs and policy headline targets.

\section{Data}

Given the cross-country nature of the European 20/20/20 goals and their policies, we constructed a longitudinal data-set for all 28 EU countries between 2005 and 2012. Note, however, that as well as evaluating the 20/20/20 goals, we also consider the way in which the CCMTs can help achieve these goals. For this reason, we are interested in the timeframes of the different policies in the climate and energy package, as well as the longer time horizon. Our final sample includes 224 observations. We obtained the data from three sources: PATSTAT (the official patent register of the EPO), the World Bank Database (from which we extracted commodity prices for oil, coal, and natural gas) and Eurostat (from which we obtained figures for FEC and the share of renewable 
energy in GIEC). Data for the different CCMT patent classes (obtained from PATSTAT) were aggregated to country-levels so as to match the levels of aggregation of the other covariates.

\subsection{The evolution of CCMTs between 2005 and 2012 and their link to Europe's 20/20/20 goals}

Given our specific interest in the impact of CCMTs on two of the "2020 climate and energy package" goals (i.e. 20\% increase in renewable energy sources and a 20\% reduction in FEC), we begin by examining the evolution of these specific technologies. As a proxy for green technologies, we use patent applications for CCMTs filed at the EPO. Much attention has been given to examining the strengths and weaknesses of this proxy ([31] Griliches 1990), the main drawback being that it only captures one part of the outcomes of innovative activity, as not all technological improvements are patented (voluntarily or otherwise) and some innovations might be more specifically of an organizational nature. Despite these shortcomings, patent data are a valid and frequently used measure for the innovative activity of firms, sectors, and countries.

CCMT patents are grouped under the patent class Y02 and the sub-classes Y02-B, -C, -E, and -T, created to register green technologies ([32] Veefkind et al. 2012) (see Table A1 in the Appendix for full details). Given the focus of this study, we are only interested in patents registered under superclass Y02 (reduction of total FEC) and sub-classes Y02-E (reduction of GHG emissions related to energy generation, transmission and distribution, [33] EPO 2015a) and Y02-T (CCMTs related to reduction of FEC in the transport sector [34] EPO 2015b).

Figure 5 shows that every single category of the CCMTs has grown considerably over the observation period, most notably Y02-E and $-\mathrm{T}$ category patents. Note that the fall recorded in 2012 reflects the time lag between patent application and approval; yet, if we restrict our analysis to the 2005-2011 time horizon, although the impact of CCMTs increases slightly, our overall sample size decreases. Given this trade-off, we opted to use the full sample. This means our estimates of the impact of CCMTs are conservative, given that future increases should have an even stronger impact on policy goals. Thus, if we compare these trends with the increase in the share of renewables, and with overall and sector-specific increases in energy efficiency and falls in FEC, there would appear to be a causal relationship. 
Fig. 5: CCMTs over the period 2004 to 2012 (EU Aggregates)

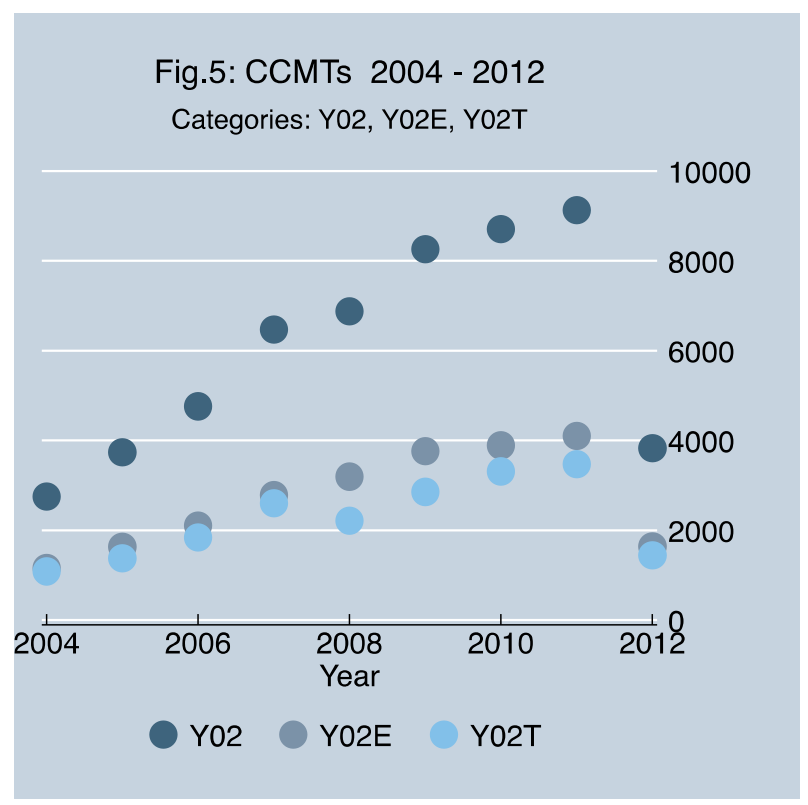

Source: PATSTAT \& Own Calculations

Since companies can access the new technologies of a given year as well as the technologies from previous years, we use patent stocks in our regressions rather than patent flows. Additionally, and following [35] Munari and Oriani (2011), the patent stock depreciates on a yearly basis to recognize the fact that knowledge becomes outdated over time. Formally, the patent stock for year $t$ and country $i$ can be created using the following equation:

$$
\text { Patent Stock }_{i, t}=(1-\delta) \text { Patent Stock }_{i, t-1}+\text { Patents }_{i, t}
$$

where Patent Stock is equivalent to the accumulated patent counts $(\mathrm{Y} 02$, Y02E, and Y02T) and Patents are the newly developed technologies of a given year. $\delta$ is the depreciation rate. We opted for a depreciation rate of 15\% per year, following [36] Jaffe (1986), [37] Cockburn and Griliches (1988), and [38] Hall and Oriani (2006). As a sensitivity analysis, we also performed all regressions using depreciation rates between 10 and 30\%, and found outcomes to be relatively stable over the whole range (in line with [36] Jaffe, 1986). In order to identify the impact of CCMTs on the policy measures (distinguishing clearly between our two main targets of interest), we employed a broad set of control variables.

\subsection{Variables for the $20 \%$ increase in the share of renewables}

We use GIEC by fuel type as our dependent variable for this specific target. Given that we are especially interested in the role of CCMTs related to energy production/consumption, our key 
variable is Y02E patent counts. Several covariates are also used. Thus, we use GDP growth rates to determine whether a country's economic performance in a given year influences GIEC. A second set of covariates includes commodity prices, since a change in the relative price of a specific commodity because of a price change in another might influence its use for energy production. The prices of oil and coal are included as regressors in our model (but not natural gas prices due to problems of multicollinearity). To account for the demand side of energy consumption, we embed the number of manufacturing enterprises in our model.

Finally, we include the number of electricity firms: if a country has a high number of such firms, it is more likely to have a higher share of renewables in its production mix than countries with just a few but dominant firms. The rationale here is that renewable energy facilities (compared to conventional power plants) are more dependent on location and country endowments and tend to produce less energy than, for example, coal-fired plants. This means that, to meet demand, more of these plants/firms are needed. We would expect a negative impact of fossil fuels on GIEC and a positive impact of renewables on GIEC.

\subsection{Variables for the $20 \%$ increase in energy efficiency}

We use FEC by fuel type as dependent variable for this specific target. As we first seek to determine the overall effect of CCMTs on total FEC, the estimate uses total FEC per country in a given year as the endogenous variable. As we are also interested in how sector-specific CCMTs contribute to an increase in energy efficiency in the transport sector, our sector-specific specification uses the FEC for this particular sector. Our core variables are the CCMTs related to each sector, comprising Y02 patent counts for total FEC and Y02T counts for that of the transport sector.

We also control for other factors that might influence FEC. Thus, we employ GDP growth rates to capture any impact of economic performance, employment rates because of their close relationship with energy consumption ([39] Tivari 2010), and the number of manufacturing firms to capture a potential causal relationship with FEC. The energy intensity of an economy and of the sectors analyzed (calculated as the ratio between FEC - total or sectoral - and real GDP for a given year and country) also form part of the specification, since, in general, we expect a greater intensity to have a positive effect on overall FEC and on consumption in the respective sectors.

The sectoral equations incorporate additional covariates to control for sector-specific trends. In the transport sector, we use the different modal splits for passenger and freight transport on both roads and rail, since a shift from one mode to the other may influence the sector's FEC. Finally, 
we include tons of goods transported per kilometer during the observation period as a measure of the quantity and performance of road transport. Table 1 presents a detailed overview of all variables used in the empirical analysis.

Table 1: Summary Statistics and Description

\begin{tabular}{|c|c|c|c|c|c|c|}
\hline VARIABLES & Description & $\mathrm{N}$ & mean & sd & $\min$ & $\max$ \\
\hline GIEC_renew & $\begin{array}{l}\text { GIEC by renewable energy sources; } 1000 \text { tons } \\
\text { of oil equivalents (TOE) }\end{array}$ & 224 & 5,321 & 6,537 & 0.500 & 32,252 \\
\hline GIEC_petrol & $\begin{array}{l}\text { GIEC by total petroleum products; } 1000 \text { tons } \\
\text { of oil equivalents (TOE) }\end{array}$ & 224 & 22,555 & 30,275 & 869.5 & 121,893 \\
\hline GIEC_gas & $\begin{array}{l}\text { GIEC by Gas; } 1000 \text { tons of oil equivalents } \\
\text { (TOE) }\end{array}$ & 224 & 15,292 & 22,807 & 0 & 85,473 \\
\hline GIEC_total & GIEC total; 1000 tons of oil equivalents (TOE) & 224 & 62,954 & 84,462 & 870.4 & 351,704 \\
\hline FEC_total & $\begin{array}{l}\text { Final energy consumption total; } 1000 \text { tons of } \\
\text { oil equivalent (TOE) }\end{array}$ & 224 & 41,006 & 53,913 & 381.5 & 223,424 \\
\hline FEC_trans & $\begin{array}{l}\text { Final energy consumption Transport; } 1000 \\
\text { tons of oil equivalent (TOE) }\end{array}$ & 224 & 13,183 & 17,743 & 197.5 & 63,406 \\
\hline gdp_growth & $\begin{array}{l}\text { Real GDP growth rate; Percentage change on } \\
\text { previous year }\end{array}$ & 224 & 1.604 & 4.331 & -14.80 & 11.90 \\
\hline oil_brent & Crude oil, Brent, $\$ /$ bbl, real 2010 & 224 & 81.95 & 15.41 & 62.07 & 104.1 \\
\hline Coal & Coal, Australia, \$/mt, real 2010 & 224 & 84.48 & 24.15 & 54.30 & 123.6 \\
\hline emp_rates & $\begin{array}{l}\text { Employment rate (15 to } 64 \text { years); annual } \\
\text { averages }\end{array}$ & 224 & 64.25 & 6.000 & 50.80 & 77.90 \\
\hline num_manu & Number of Manufacturing enterprises & 224 & 80,573 & 97,042 & 816 & 481,813 \\
\hline num_ele & $\begin{array}{l}\text { Number of enterprises belonging to the NACE } \\
\text { D category }\end{array}$ & 224 & 1,526 & 2,852 & 3 & 18,554 \\
\hline modal_pass_road & $\begin{array}{l}\text { Modal split of passenger transport; Passenger } \\
\text { cars; percentage }\end{array}$ & 224 & 81.42 & 5.317 & 64.20 & 92.30 \\
\hline modal_pass_train & $\begin{array}{l}\text { Modal split of passenger transport; Trains; } \\
\text { percentage }\end{array}$ & 224 & 5.648 & 3.177 & 0 & 12.60 \\
\hline modal_freight_rail & Modal split of freight rail transport; percentage & 224 & 19.19 & 15.99 & 0 & 70.20 \\
\hline tonnePerKilo & $\begin{array}{l}\text { Transported Tons of Freight per Kilometer; } \\
\text { Thousand Tons }\end{array}$ & 216 & 66,435 & 81,963 & 896 & 343,447 \\
\hline enrInt_total & $\begin{array}{l}\text { Energy Intensity total economy, FEC/real } \\
\text { GDP (in millions) }\end{array}$ & 224 & 0.134 & 0.0625 & 0.0586 & 0.438 \\
\hline enrInt_trans & $\begin{array}{l}\text { Energy Intensity Transport Sector, FEC/real } \\
\text { GDP (in millions }\end{array}$ & 224 & 0.0426 & 0.0171 & 0.0198 & 0.125 \\
\hline Y02_dep15 & $\begin{array}{l}\text { Patent stock for the Y02 category } \\
\text { (Depreciation Rate } 15 \% \text { ); priority date }\end{array}$ & 224 & 419.2 & 1,074 & 0 & 7,334 \\
\hline Y02E_dep15 & $\begin{array}{l}\text { Patent stock for the Y02E category } \\
\text { (Depreciation Rate } 15 \% \text { ); priority date }\end{array}$ & 224 & 186.2 & 442.8 & 0 & 3,083 \\
\hline Y02T_dep15 & $\begin{array}{l}\text { Patent stock for the Y02T category } \\
\text { (Depreciation Rate } 15 \% \text { ); priority date }\end{array}$ & 224 & 156.0 & 472.8 & 0 & 3,162 \\
\hline Number of groups & & 28 & 28 & 28 & 28 & 28 \\
\hline
\end{tabular}

Note: In the case of "tonnePerKill" no data could be obtained for Malta. We discuss possible disturbances due to this missing data in the results section. 


\section{The econometric specification}

To analyze the specific impact of CCMTs on the two key targets set by Europe's climate and energy package, two sets of estimations are performed for each goal. For the first goal - the $20 \%$ increase in energy from renewable sources - we show how the Y02E CCMTs impact the GIEC of renewable sources and also how they affect both the shares of sources other than renewables and overall consumption. We estimate the following equation for the GIEC of each fuel type:

GIEC by fuel fi,t $=\alpha_{i}+\beta_{1} Y 02 E_{-}$dep $15_{i, t}+\beta_{2}$ gdp_growth gr,t $+\beta_{3} \operatorname{coal}_{i, t}+$ $\beta_{4}$ oil_brent $_{i, t}+\beta_{5}$ num_manu $_{i, t}+\beta_{6}$ num_elec $_{i, t}+u_{i, t}$

where GIEC by fuel is a placeholder for GIEC by renewables, gas, petrol, and overall consumption. $\alpha$ is the model's constant. Y02E_dep 15 is the patent stock for the Y02E category applying a 15\% depreciation rate. Thus, the stock for the first year (2005) is the depreciated patent counts for 2004 plus the patent counts for 2005. In this way, we not only use the patent stock in the regression, but also incorporate the possibility of a delay between the patenting of a technology and its actual use in the production process. gdp_growth is the real GDP growth rate. The variables coal and oil_brent represent coal and oil prices in our regressions, respectively. The variables num_manu and num_elec represent the number of manufacturing and electricity enterprises, respectively. Finally, $u$ is the error term of the econometric specification, capturing all non-observable characteristics of GIEC. Subscripts $i$ and $t$ determine the cross-section and time dimension of the variables, respectively.

Our second set of estimations seeks to capture the overall and sector-specific impacts on FEC of CCMTs; that is, how increased energy efficiency can be achieved by employing "green" technologies. Thus, we are first interested in the effects of CCMTs on total FEC and, second, in specific CCMT effects on FEC in the transport sector. The two corresponding estimation equations are as follows:

$$
\begin{aligned}
& \text { FEC_total }{ }_{i, t}=\alpha_{i}+\beta_{1} Y 02_{-} \text {dep } 15_{i, t}+\beta_{2} \text { gdp_growth } \text { gr,t }+\beta_{3} \text { emp_rates }_{i, t}+ \\
& \beta_{4} n u m_{-} \text {manu }_{i, t}+\beta_{5} \text { enrInt_total }{ }_{i, t}+u_{i, t} \\
& F E C_{\_} \text {trans }_{i, t}=\alpha_{i}+\beta_{1} Y 02 T_{\_} d e p 15_{i, t}+\beta_{2} \text { gdp_growth } h_{i, t}+\beta_{3} \text { emp_rates }_{i, t}+ \\
& \beta_{4} n u m_{-} \text {manu }_{i, t}+\beta_{5} \text { enrInt_trans } s_{i, t}+\beta_{6} \text { modal_freight_rail } l_{i, t}+ \\
& \beta_{7} \text { modal_pass_road }{ }_{i, t}+\beta_{8} \text { modal_pass_train }{ }_{i, t}+\beta_{9} \text { tonnePerKilo }_{i, t}+u_{i, t}
\end{aligned}
$$


where FEC_total and - trans are the respective energy consumptions of total FEC and of the transport sector. $\alpha$ is the specification constant in both equations. The variables Y02_dep15 and Y02T_dep15 are the total and transport patent stocks, respectively, following the same considerations as in equations II - V. As above, gdp_growth is the annual real GDP growth rate. emp_rates represents the annual mean employment rates in our sample. num_manu stands for the number of manufacturing enterprises per country and year. enrInt_total, and -_trans are the respective energy intensities of the sectors. Additional covariates are included to capture sectorspecific dependencies.

The FEC equation for the transport sector (Eq. VII) includes the following additional variables: modal_freight_rail, modal_pass_road, modal_pass_train, and tonnePerKilo. The first three represent the modal shifts in freight and passenger transport (the modal share of road transport with respect to freight transport is not included because of problems of multicollinearity). tonnePerKilo represents tons of goods transported per kilometer by freight transport.

We opted to employ a fixed effects estimator to capture non-observable, time-invariant country heterogeneity. This approach is appropriate because country differences in population, demographics, and political systems are pronounced. By using a fixed effect estimation, we take these factors into account. The results of the Hausman test, conducted to determine whether to use fixed or random effects, however, are not conclusive in our regressions. Yet, in line with the above reasoning, we favor the use of the fixed effect specification (but, note, our main results do not vary greatly when random effects are used - results available upon request). Due to heteroscedasticity and cross-section dependency, we employ Driscoll-Kraay standard errors to obtain robust estimates of our standard errors.

\section{Results}

Below, we present the results for a $20 \%$ increase in the share of renewables (Table 2), followed by those related to energy efficiency and CCMTs (Table 3).

\section{$6.120 \%$ increase in the share of renewables and the effect of CCMTs in the energy sector}

As Table 2 shows, all the estimations present overall statistical significance, according to the corresponding F-statistic values (Eq. II-V). The goodness-of-fit of equations I-IV show high within $\mathrm{R}^{2}$ values for equations II-IV and a moderate value for equation $\mathrm{V}$. 
Table 2: Fixed Effects Estimation Results for GIEC by fuel:

\begin{tabular}{|c|c|c|c|c|}
\hline & (II) & (III) & (IV) & $(\mathrm{V})$ \\
\hline VARIABLES & GIEC_total & GIEC_renew & GIEC_petrol & GIEC_gas \\
\hline \multirow[t]{2}{*}{ Y02E_dep15 } & $-13.84 * * *$ & $4.768^{* * *}$ & $-5.904 * * *$ & $-3.308^{* * *}$ \\
\hline & $(1.632)$ & $(0.715)$ & $(0.922)$ & $(0.667)$ \\
\hline \multirow[t]{2}{*}{ gdp_growth } & $194.9^{* * *}$ & $-19.62^{* *}$ & $66.17 * * *$ & $62.98^{* *}$ \\
\hline & $(17.06)$ & $(6.654)$ & (8.778) & $(24.36)$ \\
\hline \multirow[t]{2}{*}{ Coal } & $39.46^{* * *}$ & -8.991 & $21.31 * * *$ & $28.96 * * *$ \\
\hline & $(6.760)$ & $(5.465)$ & $(2.796)$ & $(3.460)$ \\
\hline \multirow[t]{2}{*}{ oil_brent } & $-58.59 * * *$ & $29.37 * *$ & $-42.38^{* * *}$ & $-51.83 * * *$ \\
\hline & $(14.60)$ & $(8.593)$ & $(2.875)$ & $(5.486)$ \\
\hline \multirow[t]{2}{*}{ num_manu } & $0.207 * * *$ & $-0.0738^{* * *}$ & $0.189 * * *$ & $0.0661 * * *$ \\
\hline & $(0.0276)$ & $(0.0103)$ & $(0.0204)$ & $(0.00474)$ \\
\hline \multirow[t]{2}{*}{ num_ele } & $-0.443 * *$ & $0.182^{* * *}$ & $-0.499 * * *$ & 0.0628 \\
\hline & $(0.133)$ & $(0.0507)$ & $(0.107)$ & $(0.0947)$ \\
\hline \multirow[t]{2}{*}{ Constant } & $50,717 * * *$ & $8,487 * * *$ & $10,765^{* * *}$ & $12,183^{* * *}$ \\
\hline & $(3,087)$ & $(590.5)$ & $(1,526)$ & $(631.9)$ \\
\hline Observations & 224 & 224 & 224 & 224 \\
\hline Number of groups & 28 & 28 & 28 & 28 \\
\hline F-statistic & $700.6^{* * *}$ & $110.8^{* * *}$ & $173.5^{* * *}$ & $438.0 * * *$ \\
\hline $\mathrm{R}^{2}$ (within) & 0.546 & 0.638 & 0.717 & 0.239 \\
\hline
\end{tabular}

Driscoll-Kraay standard errors in parentheses

$$
\text { *** } \mathrm{p}<0.01, * * \mathrm{p}<0.05
$$

All the variables present the expected behavior. In the case of the control variables, total GIEC and GIEC by fuel type are sensitive to the overall economic performance of countries (gdp_growth), their coefficients presenting high (Eq. II, IV) to moderate (Eq. III, V) statistical significance. However, the impact of GDP growth rates differs across the four estimations. While they have a positive impact on total GIEC and on GIEC from petrol or gas sources, the impact on the share of GIEC from renewables falls with increasing GDP growth rates. This suggests that to meet the energy needs of a growing economy, energy producers rely more heavily on conventional fuel sources than they do on renewables; thus, there is no sign of any decoupling of energy from different sources or from economic growth. This is an interesting finding in terms of the renewable energy consumption-economic growth nexus and its four main hypotheses ([40] Sebri 2015). In the case of the impact of coal prices in our regressions for GIEC by fuel type, the resulting sign might initially be surprising, as it suggests a substitution effect of energy consumption by fuel type. Indeed, rising coal prices lead to a greater consumption of other sources (specifically, 
petrol and gas). Likewise, we observe the same impact for total GIEC, which is unsurprising if we consider that nearly $60 \%$ of total GIEC comprises GIEC from petrol and gas sources.

The same does not hold, however, for GIEC from renewable sources. Our estimation result here (Eq. II) shows no statistically significant relationship between GIEC and the prices of renewables or coal. As for crude oil prices (oil_brent), the sign and significance levels obtained are as expected. Thus, higher oil prices reduce the share of petrol and gas sources, as well as total GIEC, and have a positive effect on GIEC from renewables. This result is as expected if we recall that the largest share of GIEC is from petrol and gas sources. However, the close relationship between crude oil and natural gas should be borne in mind to understand the negative impact of rising oil prices on GIEC from gas sources ([41] Asche et al. 2006). Given that the manufacturing sector is one of the largest consumers of energy, the positive sign and high significance of the coefficient representing number of manufacturing enterprises (num_manu) in equations II, IV, and V are as expected.

Here again, the estimation result is not valid for the GIEC from renewable sources (Eq. III), since it appears that a larger manufacturing sector negatively influences the share of renewables in GIEC. To meet the energy needs of this sector, energy producers appear to rely more heavily on fossil fuels, in a similar relationship to that observed for the impact of GDP growth rates. As predicted, a higher number of energy firms in a country positively affects GIEC from renewable sources (Eq. III) and negatively impacts total GIEC and GIEC from petroleum sources (Eq. II \& IV). However, no statistically significant result was obtained for GIEC from gas sources, even though the sign obtained presents a negative impact of num_elec in equation $\mathrm{V}$.

In the case of our variable of interest - the Y02E patent stock (Y02E_dep15), all coefficients present high levels of statistical significance and their impact adheres to the underlying theory. For total sources and for sources other than renewables, the impact of energy sector CCMTs is negative with respect to GIEC (Eq. I, IV, and V) while the impact on GIEC from renewables is positively influenced by these technologies (Eq. III).

Figures 6-9 describe the impact of the energy sector CCMTs on the different GIEC by fuel type analyzed for different levels of the Y02E patent stock. The range, which indicates the impact of Y02E technologies, extends from 0 to the mean Y02E patent stock plus two times its standard deviation $(\sim 1100)$. Given that the average patent count stands at around 186, we can draw some conclusions with respect to the share of renewables, and that of other fuel sources, in GIEC. As expected, in line with the regression results in Table 2, GIEC is reduced by an increasing number of Y02E patents for total, petroleum, and gas sources (Figs. 6, 8 \& 9) and increases for those related to renewable sources (Fig. 7). 
Fig. 6: Predicted Margins of Y02E stock on GIEC total

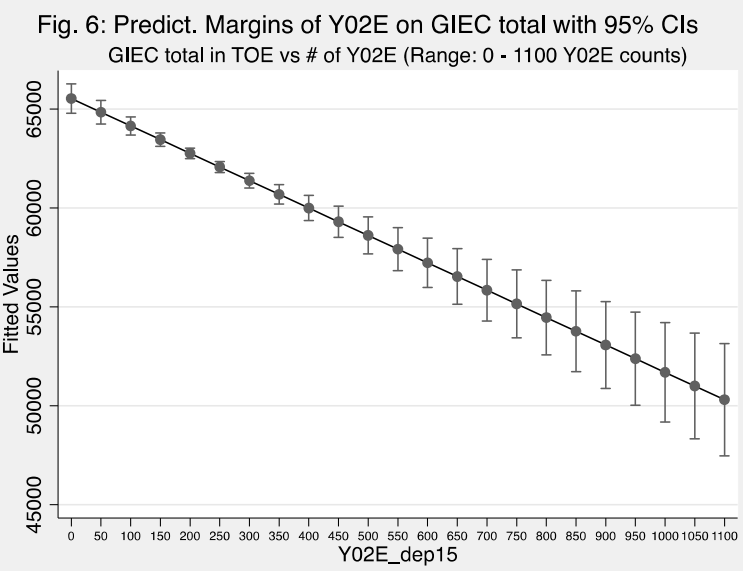

Fig. 7: Predicted Margins of Y02E stock on GIEC from renewables

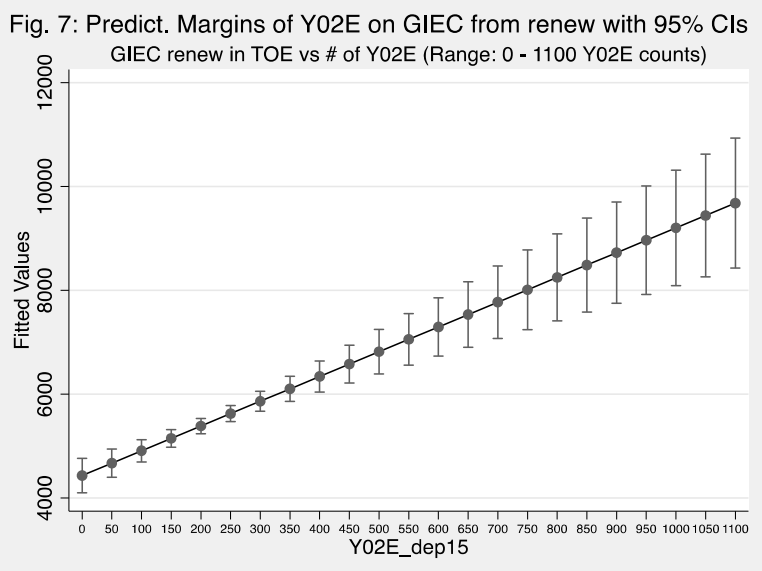

Fig. 8: Predicted Margins of Y02E stock on GIEC by petroleum

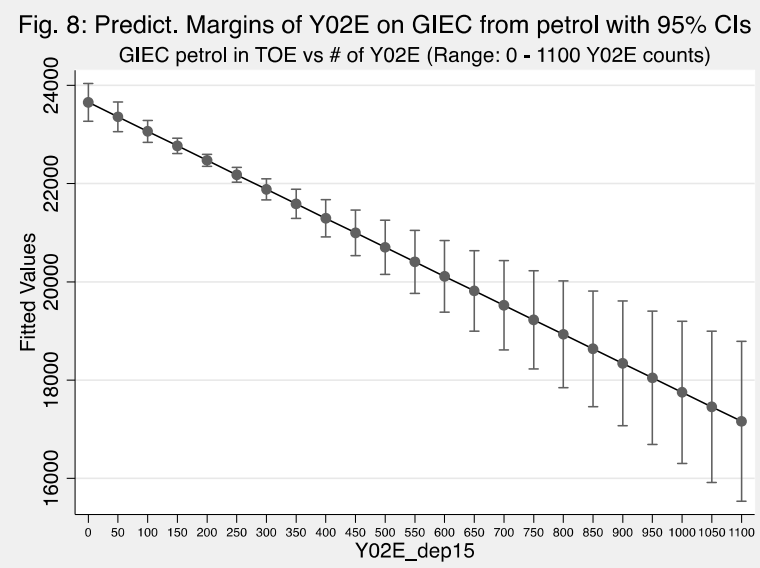

Fig. 9: Predicted Margins of Y02E stock on GIEC from gas

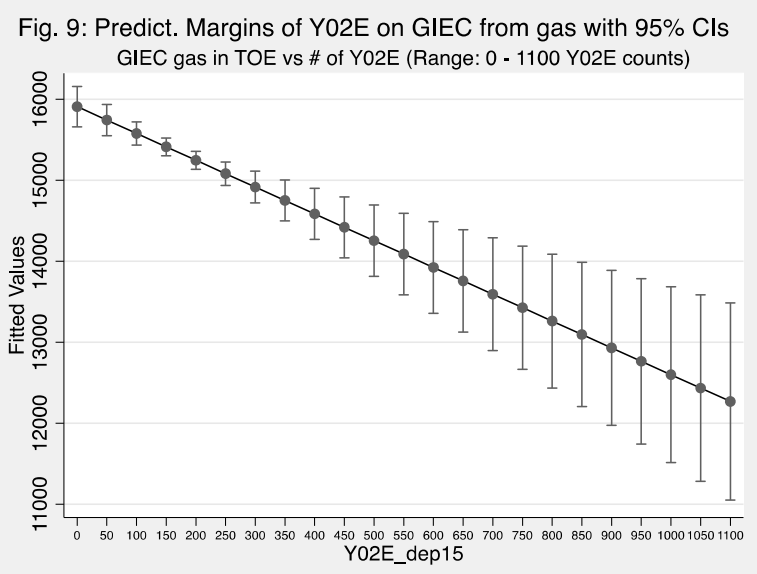

Note: Predicted margins are based on estimation results shown in Table 2

When we focus specifically on the goal of achieving a 20\% share of energy from renewables, we are interested in determining the impact on GIEC from renewables if there was an $\mathrm{X} \%$ increase in Y02E patents in our data sample. As we employ a linear prediction, that relationship can be obtained straightforwardly. For example, a 10\% increase in the Y02E patent stock over its mean would result, on average, in an increase of around 1.61\% in GIEC from renewables. A rise in the number of patents from 186 to 205 would result in an increase in GIEC from renewables of between 5,320 TOE and 5,406 TOE, on average. Indeed, a scenario in which CCMTs increase by $10 \%$ is not rare. In our data sample, the Y02E patent stock increased by $10 \%$ between 2009 (227 Y02 patents) and 2010 (249 Y02 patents). This result underlines the important role that CCMTs can play in meeting the goal of a $20 \%$ share of renewables in gross FEC. Hence, policies fostering the innovation and deployment of these technologies can be critical in achieving this target. 
Finally, as shown in Table 2, all the covariates that have a positive effect on total GIEC and on GIEC from petroleum and gas have a negative impact on GIEC from renewables, and vice versa. This observation may be important in designing future policies targeting GIEC from different fuel sources.

\section{$6.220 \%$ increase in energy efficiency}

Table 3 presents the impact of CCMTs with respect to the target of a $20 \%$ increase in energy efficiency, together with various covariates for total FEC and for FEC by end-use sector. Equations (VI) and (VII) are statistically significant, as shown by the F-statistic values. The proportion of variability of the dependent variables explained, as expressed by the $\mathrm{R}^{2}$ statistic, extends from around $46 \%$ for total FEC to around $74 \%$ for FEC in the transport sector. Note that for regression (VII) only 216 observations were available, as a full set of covariate data was not available for Malta. However, given the overall size of Malta, any potential disturbance created by not including these data should be minimal. As with the previous results, we first discuss the impacts of our control variables and then focus on the effects of CCMTs in our regressions.

The first variable that all three estimations in Table 3 share is gdp_gowth, representing real GDP growth rates. The variable presents a moderately positive statistical significance only in the case of total FEC (Eq. VI), but not for the sectoral equation (VI), suggesting that shocks such as the global economic recession did not influence FEC across the EU countries in the transport sector. This result is in line with Fig. 6, where total FEC was related to economic performance, whereas FEC in the transport sector did not fluctuate during the years of recession or recovery, but rather fell uninterrupted.

The expected positive link between employment rates and both total FEC and FEC in the transport sector was recorded, indicating that both rates of consumption are sensitive to the overall employments rates of a given country and year. Likewise, the total number of manufacturing enterprises influences total FEC and FEC in the transport sector. The reasons for the positive and statistically significant impact on total FEC are the same as those outlined for Eq. II in Table 2, whereas the positive and significant sign in the case of the transport sector reflects the close link between the manufacturing and transport sectors with the latter supplying the former.

The last of the variables that the two equations (Eq. VI-VII) have in common is the respective levels of energy intensity (enrInt_total, and -_trans). In each case, the coefficient indicates a positive impact on the respective rates of FEC and is statistically significant at the $1 \%$ level, thus capturing the general trends in overall FEC and in consumption across sectors. 
Table 3: Fixed Effects Estimation Results for FEC (total, transport):

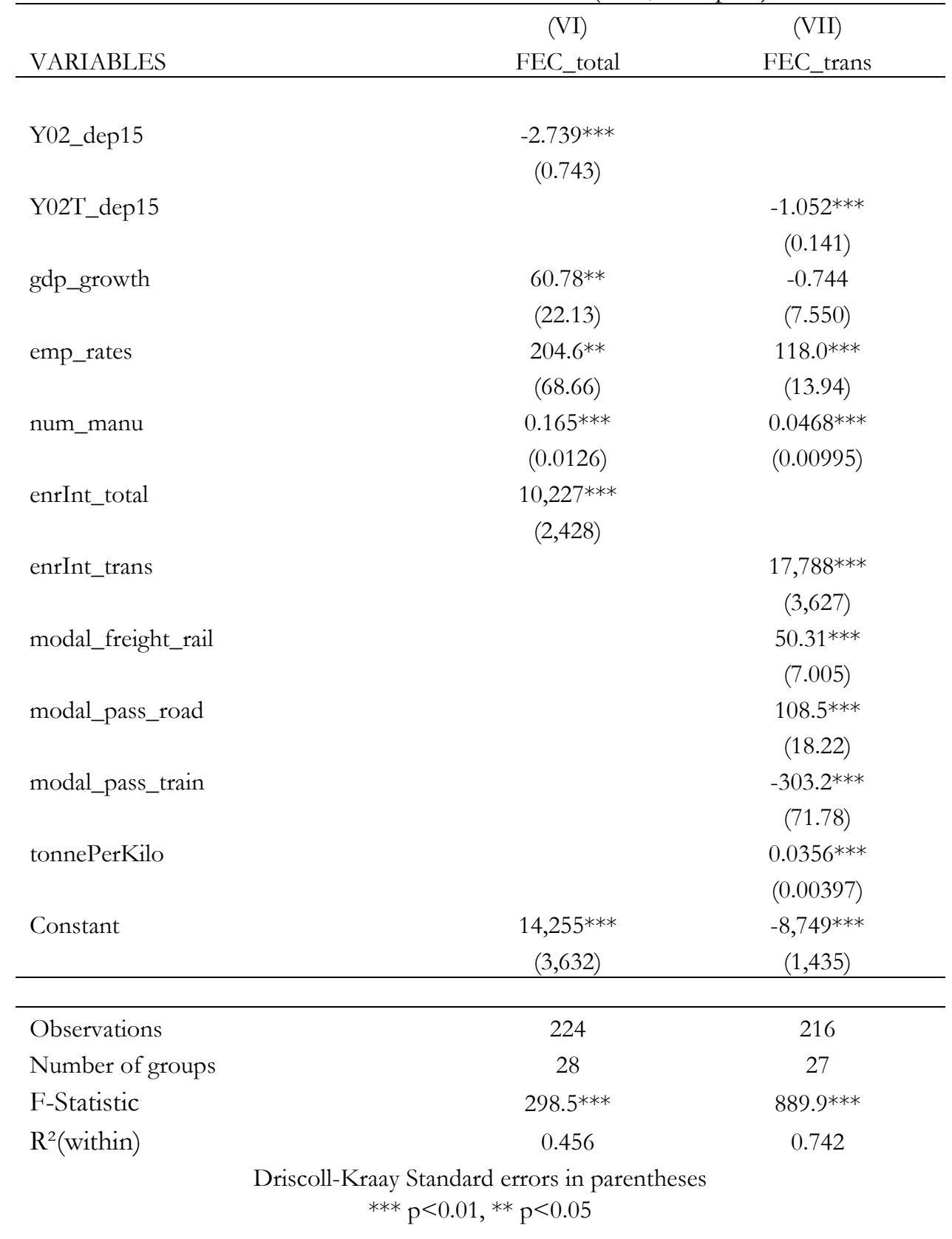

The variables that capture the specific characteristics of FEC in the transport sector (Eq. VII) all present high levels of significance. As expected, the modal splits for passenger transport (modal_pass_road, - train) highlight the fact that shifting from road- to rail-based modes in the case of passengers lowers FEC in the transport sector. However, this does not seem to hold for FEC in the rail freight transport. Here, an increasing share of rail freight transport increases FEC in the transport sector. Finally, we introduced tonnePerKilo as a load factor for road freight transport and, as expected, a positive impact is observed. 
As our main objective is to quantify the impact of CCMTs on total FEC and on FEC in the transport sector, Figures 10 and 11 show these impacts graphically and clearly indicate that FEC is reduced by an increase in CCMTs.

Fig. 10: Predicted Margins of Y02 stock on total FEC

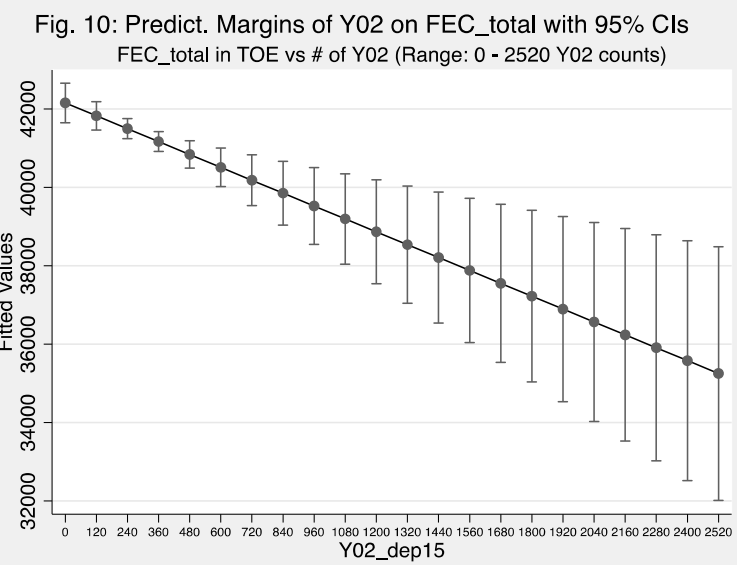

Fig. 11: Predicted Margins of Y02T stock on FEC in the transport sector

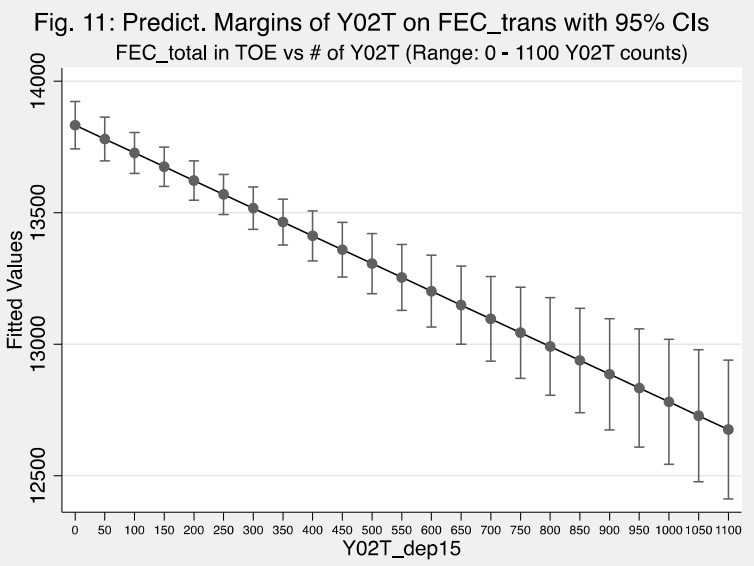

Note: Predicted margins are based on estimation results shown in Table 3

For the two different rates of FEC identified, we established different boundaries for the respective CCMT classes, since the average number of patents in each category varies from class to class. Following the same criteria as those used in Figs. 7-10, the boundaries extend from 0 to 2,520 Y02 counts for total FEC and from 0 to 1,100 Y02T counts for FEC in the transport sector. In line with the regression results, an increasing number of CCMTs reduces total FEC and FEC in the transport sector. However, this effect is not equal across the specifications. Once again, to illustrate this we increase the average number of CCMTs in our sample for each specification by $10 \%$ to determine the resulting percentage change. Table 4 summarizes the results of this exercise.

Table 4: Effect of a 10\% increase of the respective CCMT stocks on FEC

\begin{tabular}{c|c|c}
\hline $\begin{array}{c}\text { Pred. aver. FEC total given a Y02 patent } \\
\text { stock of 419 }\end{array}$ & $\begin{array}{c}\text { Pred. aver. FEC total given Y02 patent } \\
\text { stock of 461 }\end{array}$ & $\begin{array}{c}\text { Percentage } \\
\text { Change }(\%)\end{array}$ \\
\hline $\begin{array}{c}\text { 41006 TOE } \\
\begin{array}{c}\text { Pred. aver. FEC_trans given 156 Y02T } \\
\text { patent stock }\end{array}\end{array}$ & $\begin{array}{c}\text { Pred. aver. FEC_trans given 172 Y02T } \\
\text { patent stock }\end{array}$ & $\approx 0.28 \%$ \\
\hline 13668 TOE & 13651 TOE & $\approx 0.123 \%$ \\
\hline
\end{tabular}

Source: Own calculations 
As can be seen in Table 4, the impact on total FEC of CCMTs is more than twice as strong as that on FEC in the transport sector. Here, it should be borne in mind that when interpreting the resulting impact on FEC, the average yearly gross growth rates for the Y02 and Y02T patent groups exceed $10 \%$ in most cases in our data set; hence, a $10 \%$ scenario is present in our data sample and, therefore, CCMTs help to reach the goal of a $20 \%$ increase in energy efficiency. However, the impact of CCMTs on energy efficiency (measured here as FEC) remains limited, although this could be the result of the non-appliance of these new-to-the-market technologies. Hence, extending the use of these technologies could be critical in determining whether the target of a $20 \%$ increase in energy efficiency is achieved or not.

\section{Conclusion}

We have analyzed and assessed the role that CCMTs play in meeting two of the three headline targets of the "energy and climate package". In so doing, we related the goal of obtaining $20 \%$ of gross final energy consumption from renewables with energy sector technologies (Y02E-patents) and the goal of achieving a $20 \%$ increase in energy efficiency with overall technological change (Y02-patents) and sector specific changes for the transport (Y02T-patents) sector. Our results show that CCMTs play an essential role in overall target achievement, but that there are significant differences in the impact of these technologies between sectors. An increasing number of CCMTs related to energy production, transformation and distribution has a particularly marked impact on the share of energy obtained from renewable sources. A 10\% increase in Y02E patents increases the GIEC from renewables by around 1.61\%. Fostering the development of these technologies is therefore crucial for achieving the target of a $20 \%$ share from renewables.

The results from the empirical exercise point to a strong, negative and statistically significant impact on fuels other than renewables from the development of Y02E patents. This finding suggests that promoting the development of technologies of this type would lead to a considerable decrease in GIEC from fossil fuels, and also to a reduction of dependency on these sources.

In the case of the second target - achieving a 20\% increase in energy efficiency, our results suggest, first, that the impact of CCMTs has been limited to date (especially compared to the impact of CCMTs on the first target). Second, the impact of CCMTs varies greatly between total FEC and FEC in the transport sector. When we tested a scenario in which total CCMTs and sector-specific CCMTs were increased by $10 \%$, the resulting decrease in total FEC was around $0.28 \%$, compared 
to $0.123 \%$ for FEC in the transport. These results indicate that technological change does not affect FEC evenly across sectors.

These results have several policy implications. First, technological change can play a key role in achieving the climate goals set by the EU and policies such as the NER 300 program can make the difference as to whether these goals are met or not. Thus, expanding these policies and creating additional incentives for firms to innovate would help to place the EU on a low-carbon pathway. Furthermore, policies like the EU ETS seem to encourage the use of new technologies. This is very clear if we compare the effects of CCMTs on the energy sector, which is subject directly to the policy, and the effects of CCMTs on firms that are not covered by it, such as those in the transport sector. This leads to our second policy recommendation: policies need to foster the development of these technologies and ensure that end-users employ them across a range of sectors. In short, it is necessary to promote the application of new CCMTs. This might result in the increased impact of these technologies in the transport sector (among others), where the effect to date has been limited.

We are aware that problems of data availability have limited our evaluation to some degree. While we have been able to separate the impact of CCMTs on total FEC and that on FEC in the transport sector, a more detailed breakdown would be desirable so that we might extend our analysis to include, for example, such sectors as manufacturing and waste. Finally, and in order to verify our results, follow-up studies would benefit from a higher data resolution, which would allow us to detect the effects with greater precision.

\section{Acknowledgments:}

We acknowledge support from the Catalan Government under Project SGR2014-325 and the Spanish Government under Project ECO2016-76866-R.

\section{References}

[1] Edenhofer, O., R. Pichs-Madruga, Y. Sokona, E. Farahani, S. Kadner, K. Seyboth, A. Adler, I. Baum, S. Brunner, P. Eickemeier, B. Kriemann, J. Savolainen, S. Schlömer, C. Von Stechow, T. Zwickel and J.C.Minx (eds.) 2014. Climate Change 2014: Mitigation of Climate Change. Contribution of Working Group III to the Fifth Assessment Report of the Intergovernmental Panel on Climate Change. Cambridge University Press, Cambridge (UK) and New York, NY.

[2] European Commission. 2010. EUROPE 2020, European Commission, Brussels.

[3] European Commission. 2016. 2020 climate \& energy package, European Commission, Brussels. 
[4] Eurostat. 2014a. Europe 2020 indicators - climate change and energy. Link: http://ec.europa.eu/eurostat/statistics-explained/index.php/Europe 2020 indicators climate change and energy, viewed: 15.03.2016

[5] Bel, G. \& Joseph, S. 2015. Emission abatement: Untangling the impacts of the EU ETS and the economic crisis. Energy Economics 49, 531-539.

[6] Herring, H. 2006. Energy Efficiency - a critical view. Energy 31, 10-20

[7] European Commission. 2009. DIRECTIVE 2009/28/EC, European Commission, Brussels.

[8] Regiringskanslet. 2010. The Swedish National Action Plan for the promotion of the use of renewable energy in accordance with Directive 2009/28/EC and the Commission Decision of 30.06.2009, Stockholm.

[9] Malta. 2010. Malta's National Renewable Energy Action Plan as required by Article4(2) of Directive 2009/28/EC. Malta

[10] European Commission. 2015. DIRECTIVE (EU) 2015/1513, European Commission, Brussels.

[11] Environmental Protection Agency (EPA). 2016. Global Greenhouse Gas Emissions Data. Link: https://www3.epa.gov/climatechange/ghgemissions/global.html . Viewed: 17.03.2016

[12] NASA. 2016. Global Climate Change. Link: http://climate.nasa.gov/causes/ . Viewed: 17.03.2016

[13] Eurostat. 2014b. Glossary: Primary energy consumption. Link: http:/ / ec.europa.eu/eurostat/statisticsexplained/index.php/Glossary:Primary energy consumption . Viewed: 17.05.2016

[14] European Commission. 2012. DIRECTIVE 2012/27/EC, European Commission, Brussels.

[15] European Commission. 2013. Implementing the Energy Efficiency Directive - Commission Guidance, European Commission, Brussels.

[16] The Coalition for Energy Savings. 2013. EU Energy Efficiency Directive (2012/27/EU) Guidebook for Strong Implementation. Brussels.

[17] Eurostat 2016a. Greenhouse gas emissions statistics. Link: http://ec.europa.eu/eurostat/statisticsexplained/index.php/Greenhouse gas emission statistics. Viewed: 17.10.16

[18] Javid, R.J., Nejat, A., Hayhoe, H. 2014. Selection of C02 mitigation strategies for road transportation in the United States using a multi-criteria approach. Renewable Sustainable Energy Reviews 38, 960 - 972

[19] Hicks, J.R. 1932. The Theory of Wages. MacMillan, London.

[20] Porter, M.E. \& van der Linde, C. (1995). Toward a New Conception of EnvironmentalCompetitiveness Relationship. The Journal of Economic Perspectives 9(4), 97-118. 
[21] Popp, D. 2003. Pollution Control Innovations and the Clean Air Act of 1990. Journal of Policy Analysis and Management 22, 641-660.

[22] Johnstone, N., Hascic, I., Popp, D. 2010. Renewable Energy Policies and Technological Innovation: Evidence Based on Patent Counts. Environmental and Resource Economics 45, $133-155$.

[23] Haščič I., Johnstone N., Watson F, Kaminker C. 2010. Climate Policy and Technological Innovation and Transfer: An Overview of Trends and Recent Empirical Results. OECD Environment Working Papers, No. 30, OECD Publishing

[24] Calel, R. \& Dechezleprêtre, A. 2016. Environmental Change and Directed Technological Change: Evidence from the European carbon market. Review of Economics and Statistics 98, 173-191.

[25] Soltmann, C., Stucki, T., Woerter, M. 2014. The Impact of Environmental Friendly Innovations on Value Added. Environmental and Resource Economics 62, 457-479

[26] Jaffe, B.A. \& Palmer, K. 1997. Environmental Regulation and Innovation: A Panel Data Study. Review of Economics and Statistics 79, 610-619.

[27] Jaffe, B.A., Newell, R.G., Stavins, R.N. 2002. Environmental Policy and Technological Change. Environmental and Resource Economics 22, 41-69

[28] Popp, D. 2006. International innovation and diffusion of air pollution control technologies: the effects of $\mathrm{NOx}$ and $\mathrm{SO}_{2}$ regulation in the U.S., Japan, and Germany. Journal of Environmental Economics and Management 51(1), 46-71

[29] Anderson, B., Convery, F., Di Maria, C. 2011. Technological Change and the EU ETS: the case of Ireland. IEFE Center for Research on Energy and Environmental Economics and Policy, 43.

[30] Fontini, F. \& Pavan, G. 2014. The European Union Emission Trading System and technological change: The case of the Italian pulp and paper industry. Energy Policy 68, 603607.

[31] Griliches, Z. 1990. Patent Statistics as Economic Indicators: A Survey Part I. NBER WP Series.

[32] Veefkind, V., Hurtado-Albir, J., Angelucci, S., Karachalios, K., Thumm, N. 2012. A new EPO classification scheme for climate change mitigation technologies. World Patent Information 34, 106-111.

[33] EPO. 2015a. Cooperative Patent Classification - Y02E. European Patent Office, Munich.

[34] EPO. 2015b. Cooperative Patent Classification - Y02T. European Patent Office, Munich.

[35] Munari, F. and Oriani, R. 2011. The Economic Valuation of Patents - Methods and Applications. Edward Elgar, Cheltenham, UK. ISBN: 9781848445482 
[36] Jaffe, B.A. (1986). Technological Opportunity and Spillovers of R\&D: Evidence from Firms' Patents, Profits and Market Value. The American Economic Review 76, 984-1001

[37] Cockburn, I. \& Griliches, Z. (1988). Industry Effects and Appropriability Measures in the Stock Markets's Valuation of R\&D and Patents. The American Economic Review 78, 419-423

[38] Hall, B.H. \& Oriani, R. (2006). Does the market value R\&D investment by European firms? Evidence from a panel of manufacturing firms in France, Germany, and Italy. International Journal of Industrial Organization 24, 971-933

[39] Tiwari, A. 2010. On the dynamics of energy consumption and employment in public and private sector. MPRA Munich Personal RePEc Archive.

[40] Sebri, M. 2015. Use renewables to be cleaner: Meta-analysis of the renewable energy consumption-economic growth nexus. Renewable Sustainable Energy Reviews 42, 657 - 665

[41] Asche, F., Osmundsen, P., Sandsmark, M. 2006. The UK Market for Natural Gas, Oil, and Electricity: Are the Prices Decoupled? The Energy Journal 27/2, 27-40

[42] European Environmental Agency. 2009. Final Energy Consumption - outlook from IEA. Link: $\quad$ http://www.eea.europa.eu/data-and-maps/indicators/final-energy-consumptionoutlook-from-iea . Viewed: 17.05.2016

[43] European Environmental Agency. 2015. Share of renewable energy in gross final energy consumption. Link:http://www.eea.europa.eu/data-and-maps/indicators/renewable-grossfinal-energy-consumption-4/assessment. Viewed: 17.05.2016

[44] Eurostat. 2016b. Gross inland energy consumption by fuel type (tsdcc320). Link: http://ec.europa.eu/eurostat/cache/metadata/EN/tsdcc320 esmsip.htm Viewed: 17.05.2016 


\section{Appendix:}

Definition of the different types of energy consumptions discussed in this study:

\section{Primary Energy Consumption:}

Primary energy consumption measures a country's total energy demand and includes the consumption of the energy sector itself, losses during the transformation (for example, from oil or gas into electricity) and distribution of energy, and the final consumption by end users. It excludes energy carriers used for non-energy purposes (such as petroleum not used for combustion but for producing plastics) ([13] Eurostat 2014 (b)).

\section{Final Energy Consumption}

Final energy consumption includes all the energy supplied to the final consumer for all energy uses. It is usually disaggregated into the final end-use sectors: industry, transport, households, services and agriculture ([42] European Environmental Agency 2009).

\section{Gross Final Energy Consumption}

Energy commodities delivered for energy purposes to final consumers (industry, transport, households, services, agriculture, forestry and fisheries), including the consumption of electricity and heat by the energy branch for electricity and heat production and including losses of electricity and heat in distribution and transmission ([43] European Environmental Agency 2015).

\section{Gross Inland Energy Consumption}

Gross Inland Energy Consumption (GIEC) is the quantity of energy, expressed in oil equivalents, consumed within the national territory of a country. It is calculated as follows: primary production + recovered products + total imports + variations of stocks - total exports - bunkers. It corresponds to the addition of final consumption, distribution losses, transformation losses and statistical differences ([44] Eurostat 2016b). 
Table A1: The Y02 patent class and exemplary sub-class Y02T (CPC classification)

\begin{tabular}{|c|c|c|}
\hline $\begin{array}{l}\text { Patent } \\
\text { Class }\end{array}$ & Definition & Examples \\
\hline Y02 & \multicolumn{2}{|c|}{ Climate Change Mitigation Technologies } \\
\hline \multicolumn{3}{|c|}{ Subclass Y02E } \\
\hline Y02E & \multicolumn{2}{|c|}{$\begin{array}{l}\text { Reduction of GHG emissions related to energy generation, transmission or } \\
\text { distribution }\end{array}$} \\
\hline Y02E10/00 & $\begin{array}{l}\text { Energy generation through } \\
\text { renewable energy sources }\end{array}$ & $\begin{array}{l}\text { Geothermal Energy / Hydro Energy / } \\
\text { Energy from Sea / Photovoltaic } \\
\text { (PV)Energy / Thermal-PV hybrids / } \\
\text { Wind Energy }\end{array}$ \\
\hline $\begin{array}{l}\mathrm{Y} 02 \mathrm{E} \\
20 / 00\end{array}$ & $\begin{array}{l}\text { Combustion technologies with } \\
\text { mitigation potential }\end{array}$ & $\begin{array}{l}\text { Combined combustion / Technologies } \\
\text { for a more efficient combustion or heat } \\
\text { usage }\end{array}$ \\
\hline $\begin{array}{l}\mathrm{Y} 02 \mathrm{E} \\
40 / 00\end{array}$ & $\begin{array}{l}\text { Technologies for an efficient } \\
\text { electrical power generation, } \\
\text { transmission or distribution }\end{array}$ & $\begin{array}{l}\text { Flexible AC transmission systems / } \\
\text { Active power filtering / Reactive power } \\
\text { compensation }\end{array}$ \\
\hline
\end{tabular}

Subclass Y02T

\begin{tabular}{|c|c|c|}
\hline Y02T & \multicolumn{2}{|c|}{ Climate Change Mitigation Technologies related to Transportation } \\
\hline Y02T 10/00 & $\begin{array}{l}\text { Road transport of goods or } \\
\text { passengers }\end{array}$ & $\begin{array}{l}\text { Internal combustion engine [CE] based } \\
\text { vehicles / Exhaust after-treatment / Use } \\
\text { of alternative fuels }\end{array}$ \\
\hline Y02T 30/00 & $\begin{array}{l}\text { Transportation of goods or } \\
\text { passengers via railways }\end{array}$ & $\begin{array}{l}\text { Energy recovery technologies concerning } \\
\text { the propulsion system in locomotives or } \\
\text { motor railcars / Reducing air resistance } \\
\text { by modifying contour }\end{array}$ \\
\hline Y02T 50/00 & Aeronautics or air transport & $\begin{array}{l}\text { Drag reduction / Weight reduction / On } \\
\text { board measures aiming to increase energy } \\
\text { efficiency }\end{array}$ \\
\hline
\end{tabular}

